IRRITABLE BOWEL SYNDROME

\title{
Diarrhoea-predominant IBS patients show mast cell activation and hyperplasia in the jejunum
}

\author{
Mar Guilarte, Javier Santos, Inés de Torres, Carmen Alonso, María Vicario, Laura Ramos, Cristina \\ Martínez, Francesc Casellas, Esteban Saperas, Juan Ramón Malagelada
}

Gut 2007;56:203-209. doi: 10.1136/gut.2006.100594

See end of article for authors' affiliations

Correspondence to Dr Javier Santos, Digestive Diseases Research Unit, Institut de Recerca Vall d'Hebron, Hospital General Vall d'Hebron, Paseo Vall d'Hebron 119-129, 08035 Barcelona, Spain; jsantos@ ir.vhebron.net

Revised 16 August 2006 Accepted 17 August 2006 Published Online First 27 September 2006
Background: Increased numbers of mast cells and mast cell activation in distal gut segments are associated with symptom onset and severity in irritable bowel syndrome (IBS). Although upper gut symptoms are common, mast cells have not been thoroughly evaluated in proximal gut in IBS patients.

Methods: Jejunal biopsies obtained by Watson's capsule, aspiration of intestinal fluid and one blood sample were obtained in 20 diarrhoea-predominant patients with IBS (D-IBS) and 14 healthy volunteers $(H)$. Psychological stress (Holmes-Rahe Scale) and depression (Beck's Depression Inventory) were evaluated at baseline and food and respiratory allergy excluded. Biopsies were processed for H\&E staining and microscopic inflammation assessed by counting intraepithelial lymphocytes. Mast cells in lamina propria were counted by immunohistochemistry with CD1 17 (c-kit). Tryptase concentration was measured in intestinal fluid and serum.

Results: D-IBS patients showed higher psychological stress than healthy volunteers (D-IBS: 203 (SD 114) $v \mathrm{H}$ : 112 (SD 99); $p=0.019$ ). Immunohistochemical staining of jejunal mucosa revealed mild increase in intraepithelial CD3+ cells in D-IBS patients (D-IBS: 15.3 (SD 5.5; 95\% Cl 12.7 to 17.9) $v \mathrm{H}: 10.3$ (SD 3.9; $95 \% \mathrm{Cl} 8.0$ to 12.5$) ; p=0.006)$. Moreover, $D$-IBS patients showed marked increase in mast cells numbers (DIBS: 34 (SD 9.3); H: 15.3 (SD 4.4) mast cells/hpf; $p<0.001$ ) and higher tryptase concentration in jejunal fluid (D-IBS: 0.45 (SD 0.38); H: 0.09 (SD 0.10) $\mu \mathrm{g} / \mathrm{l} ; \mathrm{p}=0.005$ ). Upper gut symptoms were not associated with gender, mast cell counts, jejunal tryptase or basal stress.

Conclusion: This jejunal mucosal inflammatory profile may help identify diarrhoea-predominant IBS, a stressrelated disorder. rritable bowel syndrome (IBS) is a common disorder that affects a heterogeneous group of patients experiencing chronic and recurrent abdominal pain usually associated with visceral hypersensitivity and altered bowel habit. ${ }^{1}$ IBS has been considered a prototypic gut functional disorder since no reliable biological markers are readily available. Different clinical subtypes of IBS are apparent, although differences in their pathophysiology and aetiology have not been clearly established. Recently, interest has focused on the presence of mucosal inflammation and the putative role of immune cells and environmental factors, such as chronic stress, in the generation and perpetuation of this inflammatory process, factors that may be particularly valid for diarrhoea-predominant IBS. ${ }^{2}{ }^{3}$

The role of stress and stressful events is well recognised in patients with functional gastrointestinal disorders, and IBS patients appear to be at risk of suffering from psychosocial stress. ${ }^{4}$ Clinical and epidemiological studies also indicate that in certain diarrhoea-predominant IBS patients symptom intensity and durability depends, to a great extent, on the presence of chronic stress as a co-morbid factor. ${ }^{35}$ Indeed, stress alters intestinal motility, ${ }^{67}$ enhances visceral perception, ${ }^{89}$ reactivates gut mucosal inflammation ${ }^{10}{ }^{11}$ and disturbs epithelial function ${ }^{12}$ in both animal models and humans, and these changes have been also observed in diarrhoea-predominant IBS patients. However, the pathway linking stress with IBS pathophysiological abnormalities and symptoms has not been precisely characterised.

The stress-mast cell axis is a putative pathway whose investigation may help us understand the relationship of stress with the generation of certain pathophysiological characteristics associated with IBS. Mast cells participate in the regulation of intestinal motility, visceral sensitivity and mucosal and epithelial gut barrier function, ${ }^{13}$ and both acute ${ }^{14}$ and chronic stress ${ }^{15}$ induce intestinal mast cell activation. Anatomical contacts between mast cells and enteric nerve fibres have been demonstrated in the human gastrointestinal mucosa and increase when inflammation is present.9 ${ }^{16}{ }^{17}$ Moreover, increased mast cell numbers and mast cell products have been described in the terminal ileum and the proximal and distal colon of IBS patients. ${ }^{17-19}$ The mast cell-enteric nerve interaction provides a physical substrate for bidirectional communication between the central nervous system and the gut, by which stress might influence gastrointestinal physiology.

Finally, epidemiological studies have shown that IBS patients often complain of dyspeptic symptoms. ${ }^{20}{ }^{21}$ Although preliminary findings may suggest enhanced activation of jejunal mast cells after administration of stress-like hormones in IBS diarrhoea, ${ }^{22}$ evaluation of upper gut mucosal inflammation and mast cell status in these patients is lacking. Thus, our aim was to investigate whether diarrhoea-predominant IBS patients showed mast cell infiltration and activation in the jejunum.

\section{METHODS}

\section{Participants}

Newly diagnosed diarrhoea-predominant IBS (D-IBS) patients fulfilling Rome II criteria, ${ }^{23}$ and healthy volunteers were prospectively recruited from the outpatient gastroenterology clinic and by public advertising, respectively. A complete medical history and physical examination were carried out

Abbreviations: $D$, diarrhoea-predominant; $\mathrm{H}$, healthy volunteers; hpf, high power field; IBS, irritable bowel syndrome; IELs, intraepithelial lymphocytes; MC, mast cells 
Table 1 Investigations performed in study participants

\begin{tabular}{lll}
\hline & Healthy & D-IBS \\
\hline Upper endoscopy & 0 & $14 / 20$ \\
Colonoscopy and biopsy & 0 & $4 / 20$ \\
Jejunal biopsy and aspirate & $14 / 14$ & $20 / 20$ \\
Blood biochemical profile & $14 / 14$ & $20 / 20$ \\
$\begin{array}{l}\text { Coeliac serology and thyroid } \\
\text { function }\end{array}$ & 0 & $20 / 20$ \\
$\begin{array}{l}\text { Stool culture and microscopy } \\
\text { Skin prick tests }\end{array}$ & 0 & $20 / 20$ \\
$\begin{array}{l}\text { Abdominal imaging (barium, } \\
\text { sonography, tomography) }\end{array}$ & $14 / 14$ & $20 / 20$ \\
\hline
\end{tabular}

Upper endoscopy was performed only in patients experiencing dyspepsia. In four of the D-IBS patients a colonoscopy and biopsy were performed showing $<20$ CD3+ cells $/ 100$ surface epithelial cells, excluding lymphocytic colitis.

and compliance with functional dyspepsia according to Rome II criteria $^{24}$ checked in all participants. All D-IBS patients experienced daily watery or mushy stools that varied in number (3 to 12/day) associated with abdominal pain or discomfort that was relieved with defecation. Candidates were also evaluated by allergists to rule out food and respiratory allergy. A battery of prick skin tests (Laboratorios Leti, Barcelona, Spain) for 32 common foodstuffs and 24 inhalants was administered prior to biopsy using histamine and saline as positive and negative controls, respectively. Reasonable exclusion of other gastrointestinal diseases was achieved in IBS patients by means of a broad biochemical and serological profile including antitransglutaminase and anti-endomisium antibodies, upper and lower endoscopy, abdominal sonography and barium studies, when considered necessary by the responsible physician (table 1). Previous history of acute gastroenteritis and its relationship to the initiation of IBS symptoms was carefully recorded.

None of the participants was allowed to take antihistamines, ketotifen, nedocromil, cromolyn, acetylsalicylates, NSAIDs, anticholinergics, theophylline, $\beta_{2}$-agonists, codeine or opioid derivatives for at least 2 weeks prior to the intestinal biopsy to prevent any effect on mast cell numbers and activation. Patients having taken steroid or immunosuppressive drugs any time in the last 6 months were not included.

Written informed consent was obtained from each participant. The study was approved by the ethics committee of the hospital and conducted according the revised Declaration of Helsinki.

\section{Baseline stress and depression levels}

Stress levels were measured using the Spanish version of the Modified Social Readjustment Scale of Holmes-Rahe. ${ }^{25}$ This validated questionnaire reflects the occurrence of significant life events in the last year of life and allows stratification of participants as suffering from low (0-150), moderate (151-300) or severe $(>300)$ stress.

Depression was evaluated using the Spanish version of Beck's Depression Inventory ${ }^{26}$ and participants classified as suffering from low (10-18), moderate (19-29) or severe (>30) depression. Both questionnaires were filled in by participants the same day as the jejunal biopsy.

Jejunal biopsy, fluid content aspirate and blood sample Jejunal biopsy was performed within 3 weeks after inclusion. The day of the biopsy all patients were clinically symptomatic and severity of IBS was assessed using a modified visual analogue scale, from 0 (no symptoms) to 10 (maximum), to evaluate the quality of life according to the self-perceived intensity of abdominal pain and diarrhoea. ${ }^{27}$
Mucosal biopsies and aspirates were obtained using a Watson capsule with an attached 3-mm diameter aspiration tube. After an overnight fast, the instrument was orally inserted under fluoroscopic control, between 08:00 and 10:00 h, to the proximal jejunum, $5-10 \mathrm{~cm}$ distal to the Treitz's angle. Jejunal fluid $(5 \mathrm{ml})$ was obtained by gentle aspiration with a $10-\mathrm{ml}$ syringe, snap frozen and stored at $-80^{\circ} \mathrm{C}$ until analysed. A tissue sample was then obtained by suction with a $50-\mathrm{ml}$ syringe, immediately embedded in $4 \%$ buffered formalin and processed for histology and immunohistochemistry. In addition, a 5-ml blood sample was taken at the end of the study and the serum recovered and frozen until analysed.

\section{Histology and immunohistochemistry}

An experienced gastrointestinal pathologist, who was blinded to the clinical diagnosis, examined the biopsy specimens. Jejunal sample biopsy specimens were stained with H\&E for general histological examination and epithelial morphometry as performed in routine clinical practice. In particular, the presence of eosinophilic infiltration, epithelial abnormalities including villous atrophy and micro-organisms were evaluated at $\times 400$ magnification. In order to further exclude coeliac disease and lymphocytic enteritis, microscopic inflammation was also assessed by counting intraepithelial lymphocytes (IELs).

For immunohistochemistry, paraffin-embedded samples were cut in $5-\mu \mathrm{m}$ sections, the paraffin removed with xylene and the samples rehydrated. Endogenous peroxidase activity was blocked with $0.2 \%$ hydrogen peroxidase solution and nonspecific labelling was blocked in serum blocking solution. Sections were incubated in complete medium for $\mathrm{l} h$ at room temperature with $c$-kit anti-human rabbit polyclonal antibody (CD117, Dako, Carpinteria, CA, USA) at a dilution of 1:50). As a negative control the primary antibody was omitted and replaced with phosphate-buffered saline. The reaction was revealed by the avidin-biotin complex peroxidase method ( $A B C$ Elite kit, Vector, Burlingame, CA, USA) followed by staining with the peroxidase substrate 3,3'-diaminobenzidine tetrachloride (DAB; Sigma, Deisenhofen, Germany). The slides were counterstained with $50 \%$ haematoxylin. Human gastrointestinal tumour tissue was used as a positive control for c-kit expression. Samples were also processed for CD3 immunohistochemistry (Dako, Carpinteria, CA, USA) at a dilution of 1:50, using the same technique. Quantitation of mast cells and IELs (CD3+ cells) was performed on immunostained sections with a Leitz microscope (Laborlux S microscope, E. Leitz, Wetzlar, Germany) at $\times 400$ magnification. The number of cells stained for c-kit and CD3 were counted in eight contiguous nonoverlapping fields and expressed as mast cells per high power field (MC/hpf) and IELs/100 epithelial cells.

Inter-observer reproducibility of mast cells and IEL findings was tested by comparing counts against those of a second experienced pathologist. Similarly, intra-observer reproducibility was assessed by comparing counts performed on two different days by the principal pathologist ${ }^{28}$ Reproducibility in all cases was excellent (fig l) and hence results reported below are those of the principal pathologist.

\section{Blood and jejunal tryptase concentration}

Serum and jejunal concentration of the mast cell protease, tryptase, were assayed by means of a specific fluoroenzymeimmunoassay (FEIA-UniCAP, Pharmacia Diagnostics, Uppsala, Sweden). Serum samples were processed following the manufacturer's instructions and concentration expressed as $\mu \mathrm{g} / \mathrm{l}$.

To determine tryptase in intestinal fluid, jejunal fluid samples were first lyophilised to increase concentration by a 


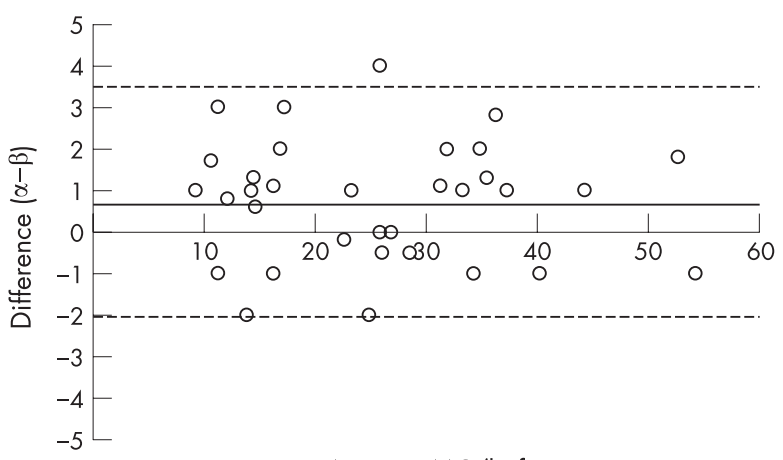

Average MC/hpf

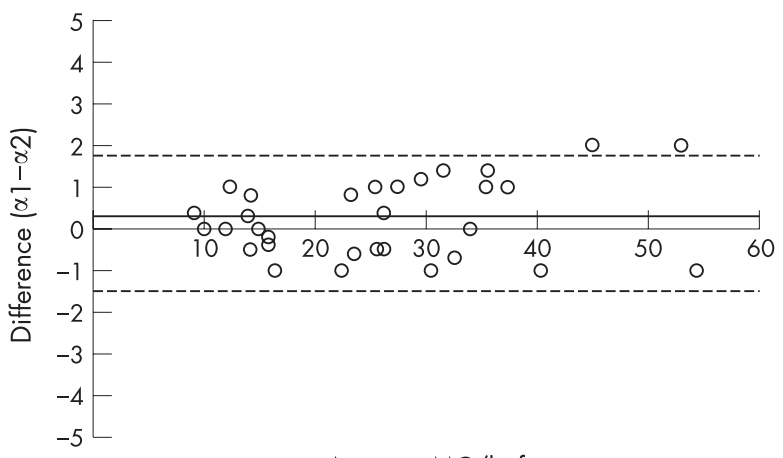

Average MC/hpf

Figure 1 Reproducibility of mast cell counts. Reproducibility of mast cell counts was assessed by comparing numbers of mast cells reported by two independent observers ( $\alpha$ and $\beta$; upper panel) or by the same observer on two separate days $(\alpha 1$ and $\alpha 2$; lower panel). Dotted lines represent $95 \%$ limits of agreement (upper panel: $(-2 ; 3.6)$, lower panel: $(-1.5 ; 1.98)$ ). Black solid lines represent the mean differences (upper: 0.77 (standard deviation (SD) 1.45); lower: 0.24 (SD 0.88)) and dots represent differences for each single measurement. Comparisons were performed by the Bland and Altman method. ${ }^{28}$

factor of 12 and reconstituted in phosphate-buffered saline with $1 \%$ bovine serum albumin and multiprotease inhibitor cocktail (dilution 1:100), containing AEBSF $104 \mathrm{mM}$, aprotinin $0.08 \mathrm{mM}$, leupeptin $2 \mathrm{mM}$, bastatin $4 \mathrm{mM}$, pepstatin $1.5 \mathrm{mM}$ and E-64 $1.4 \mathrm{mM}$ (Sigma-Aldrich, St. Louis, MO, USA). Samples were then centrifuged at $1000 \mathrm{~g}$ for $10 \mathrm{~min}$ at $4^{\circ} \mathrm{C}$, the supernatants were collected and tryptase concentration was assayed and expressed as $\mu \mathrm{g} / \mathrm{l}$ after correction according to the concentration factor. Tryptase curves were not influenced by phosphate-buffered saline, bovine serum albumin or protease inhibitors.

\section{Data expression and statistical analysis}

Data are expressed as mean (SD) (95\% confidence interval (CI)), unless otherwise stated. Non-parametric tests were used as appropriate to increase statistical assurance (Mann Whitney $\mathrm{U}$ test, Fisher's exact test and Spearman correlation test). p Values of $<0.05$ were considered significant.

\section{RESULTS}

\section{Participants}

Twenty three newly diagnosed D-IBS patients and 14 healthy volunteers were selected. Three D-IBS patients were excluded due to inadequate jejunal tissue sampling (two superficial biopsies and one gastric biopsy). There were no differences in age or gender proportions between the healthy and D-IBS populations. Interestingly, most D-IBS patients also suffered from functional dyspepsia $(70 \%)$, considered their bowel
Table 2 Demographic and clinical characteristics of participants

\begin{tabular}{lll}
\hline & Healthy & D-IBS \\
\hline Number of subjects & 14 & 20 \\
Gender, F:M & $6: 8$ & $14: 6$ \\
$\begin{array}{l}\text { Age, years (SD; range) } \\
\text { Symptom duration, }\end{array}$ & $27.9(7.8 ; 22-53)$ & $32.8(7.7 ; 21-56)$ \\
months (SD; range) & NA & $17.9(8.2 ; 8-36)$ \\
$\begin{array}{l}\text { Severity (0-10), (SD) } \\
\text { Functional dyspepsia }\end{array}$ & NA 14 & $6.8(1.5)$ \\
$\begin{array}{l}\text { Previous gastroenteritis } \\
\text { Food allergy }\end{array}$ & No & $14 / 20$ \\
$\begin{array}{l}\text { Other inflammatory } \\
\text { disorders }\end{array}$ & No & $6 / 20$ \\
Other diseases & No & No \\
& & No \\
& & $3 / 20$ (hypothyroidism, \\
& & Von Willenbrand, \\
\hline
\end{tabular}

Data are expressed as mean (SD). D-IBS, diarrhoea-predominant irritable bowel syndrome; F, female; M, male; NA, non-applicable.

symptoms as quite severe and 30\% definitely related onset of their IBS symptoms to a previous episode of acute gastroenteritis. Other demographic and clinical characteristics of the participants are shown in table 2 .

\section{Baseline stress and depression levels}

D-IBS patients showed higher stress levels at baseline than healthy volunteers (D-IBS: 203 (SD 114; 95\% CI 149 to 256) $v$ H: 112 (SD 99; 95\% CI 55 to 169), p=0.019). D-IBS patients most frequently $(13 / 20)$ scored as moderate $(39 \%)$ or severe $(28 \%)$ on the Holmes-Rahe Scale, whereas only a few of the healthy volunteers $(4 / 14)$ scored as moderate $(18.2 \%)$ or severe (9.1\%) (fig 2).

Most of our participants (75\%) were not depressed and the incidence of depression in the D-IBS group (33.3\%) was not statistically different from that of the healthy volunteers (14.3\%). However, when considering only depressed patients in both groups, D-IBS patients showed higher scores than healthy volunteers (fig 3).

\section{Histology and mucosal inflammation}

Routine histology disclosed normal epithelial architecture, no increase in the number of eosinophils and no parasites, microbial or viral inclusions and a normal or discrete lymphoplasmacitary infiltrate in the lamina propria and/or in the intraepithelial compartment with no apparent differences observed between D-IBS patients and the control group (fig 4A,B). Immunohistochemistry for CD3+ cells revealed mild increase in IEL numbers in D-IBS patients when compared to

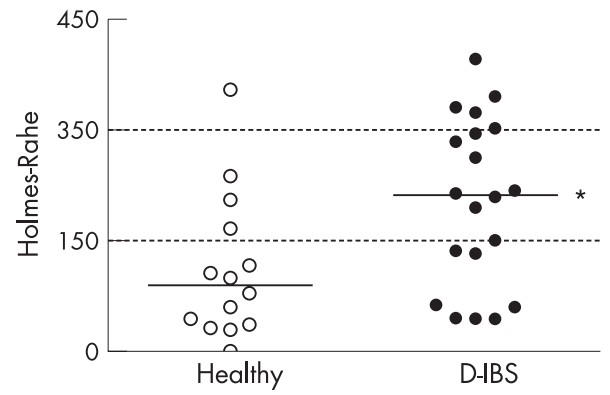

Figure 2 Baseline psychological stress levels. Psychological stress was evaluated in D-IBS patients $(n=20)$ and in healthy volunteers $(n=14)$ using the Modified Social Readjustment Scale of Holmes-Rahe. Dotted lines represent levels of stress: low (0-150), moderate (151-300) and severe $(>301)$. Black lines represent median values. ${ }^{*} \mathrm{p}=0.019$, Mann Whitney $U$ test. 


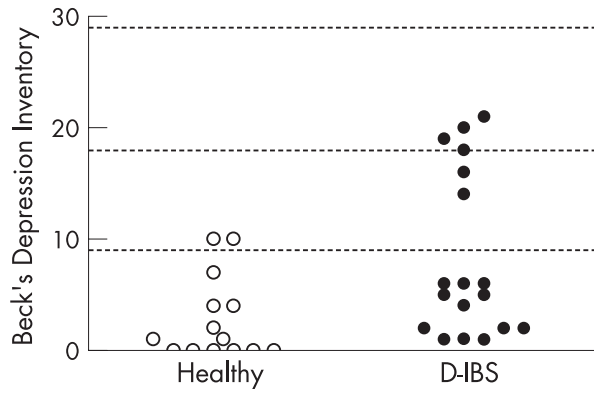

Figure 3 Baseline depression levels. Depression was evaluated in D-IBS patients $(n=18)$ and in healthy volunteers $(n=14)$ using Beck's Depression Inventory. Dotted lines represent depression levels: normal (0-9), low (1018) and moderate (19-29).

healthy volunteers (D-IBS: 15.3 (SD 5.5; 95\% CI 12.7 to 17.9) $v$ H: 10.3 (SD 3.9; 95\% CI 8.0 to 12.5 ); $\mathrm{p}=0.006$ ) (fig 5).

\section{Mast cells counts}

Mast cells (CD117+) were markedly increased in the jejunal mucosa of D-IBS patients compared to healthy volunteers (DIBS: 34.0 (SD 9.3; 95\% CI 29.5 to 38.5) $v \mathrm{H}: 15.3$ (SD 4.4; 95\% CI 12.6 to 17.9 ) MC/hpf; p $<0.001$ ) (fig 6) and the majority of these CDl17+ cells were localised within the lamina propria (fig 4C,D). Notably, only one healthy volunteer but all D-IBS patients showed more than $20 \mathrm{MC} / \mathrm{hpf}$. D-IBS dyspeptic patients showed similar mast cell numbers as non-dyspeptic D-IBS patients (32.2 (SD 9.0; 95\% CI 27.5 to 39.0) $v 31.8$ (SD 7.7; $95 \%$ CI 24.2 to 39.1) $\mathrm{MC} / \mathrm{hpf} ; \mathrm{p}=\mathrm{NS}$ ). Moreover, no differences in mast cell numbers were detected between D-IBS patients with a previous history of acute gastroenteritis and patients without such a history (32.3 (SD 5.9; 95\% CI 26.0 to 38.5 ) v 34.7 (SD 10.2; 95\% CI 28.8 to 40.6 ) MC/hpf; p=NS). Differences in mast cell numbers were not attributable to age $(\mathrm{r}=0.328(95 \% \mathrm{CI}-0.033$ to -0.61$) ; \mathrm{p}=0.066)$, stress levels $(\mathrm{r}=0.35(95 \% \mathrm{CI}-0.02$ to -0.638$) ; \mathrm{p}=0.056)$ or gender, as shown in table 3.

\section{Mast cell tryptase}

Tryptase concentration in serum was within the normal range in all participants and similar in both groups (D-IBS: 5.52 (SD 2.01; $95 \%$ CI 4.52 to 6.53 ); H: 5.40 (SD 2.15; $95 \%$ CI 3.96 to $6.85) \mu \mathrm{g} / \mathrm{l}$ ). Notably, jejunal luminal tryptase was significantly higher in D-IBS patients compared to the control group (D-IBS: 0.45 (SD $0.38 ; 95 \%$ CI 0.20 to 0.69 ) $v 0.09$ (SD 0.10 ; $95 \%$ CI 0.02 to 0.177$)) \mu \mathrm{g} / \mathrm{l}, \mathrm{p}=0.005$ ) indicating local activation of mast cells (fig 7).

No correlation was found between number of mast cells and levels of luminal tryptase. In addition, dyspeptic symptoms and IBS severity were not correlated with gender, mast cell numbers, jejunal tryptase, psychological stress or depression.

\section{DISCUSSION}

This study provides evidence of increased mast cell numbers along with mast cell activation in the jejunum of diarrhoeapredominant IBS patients. These novel findings extend those of previous studies showing mast cell hyperplasia in terminal ileum and colon of IBS patients, indicating that mucosal inflammation in D-IBS patients is not limited to the lower gut. Moreover, activation of jejunal mast cells suggests that local

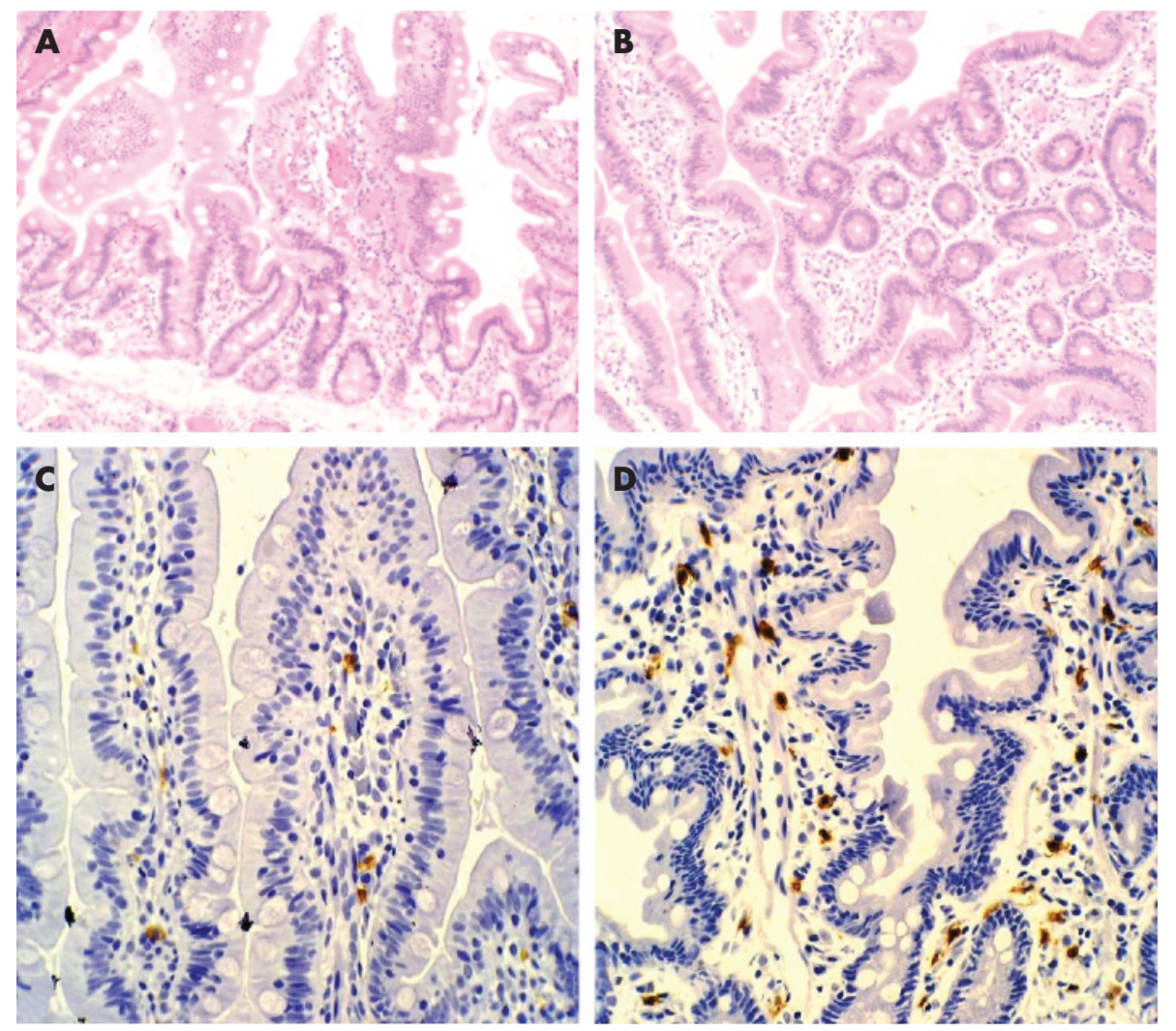

Figure 4 Jejunal histology and mast cell counts. Routine processing of jejunal samples for H\&E staining disclosed no apparent differences in epithelial architecture or the presence of inflammatory cells in the lamina propria, between healthy volunteers (A) and D-IBS patients (B). However, after immunohistochemistry for c-kit (CD 1 17, brown cells) D-IBS patients (D) showed higher mast cell numbers compared to healthy volunteers (C). Slides shown $(\times 400$ magnification) are representative of common findings. 


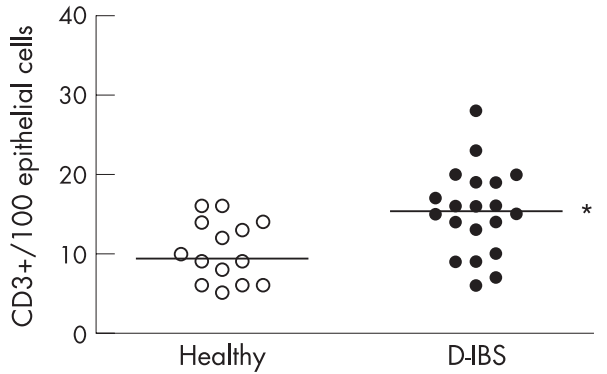

Figure 5 Jejunal intraepithelial lymphocyte (IEL) counts. IELs (CD3+ cells) were counted in eight contiguous, non-overlapping, histological fields, at $\times 400$ and expressed as IELs/100 epithelial cells after immunohistochemistry for CD3+. D-IBS patients $(n=20)$ showed an increase in IELs compared to healthy volunteers $(n=14)$. Black lines represent median values. ${ }^{*} p=0.006$, Mann Whitney $U$ test.

mast cell-mediated inflammatory events contribute to functional disturbances and clinical manifestations of D-IBS.

Despite the increasing prevalence and importance of IBS, there is no single distinctive biological marker and the diagnosis is based on clinical criteria and exclusion of other gastrointestinal disorders. ${ }^{24}$ In recent years, the conventional view of IBS as a non-organic disorder has been challenged by reports of low-grade mucosal inflammation as a relevant pathological substrate in some IBS patients (reviewed in Bercik et $a l^{2}$ ). In particular, increased numbers of inflammatory cells and chemical mediators have been identified in mucosa specimens from the ileum and colon of D-IBS patients which were apparently not hypercellular on routine histology. ${ }^{29}{ }^{30} \mathrm{In}$ agreement with those studies, we have found that the vast majority of jejunal biopsies from D-IBS patients were reported by the pathologist as being within normal limits or showing mild, usually considered as non-specific, mucosal inflammation. Moreover, specific counts of IELs, based on CD3 immunohistochemistry, revealed a 1.5 -fold increase in D-IBS jejunum further supporting the presence of low grade epithelial inflammation and making unlikely the existence of more severe inflammatory processes such as lymphocytic enteritis or coeliac disease. ${ }^{31}$ In addition, the young age of our patients also argues against microscopic colitis as an alternative diagnosis since most of these patients are in their 70s at the time of diagnosis. Although quantitative differences in inflammatory cells may be present in different studies, this can be explained by patient selection, and segmental or aetiological differences in IBS subsets. ${ }^{29}{ }^{30}$ Whether these findings may serve to differentiate aetiological (post-infectious, post-stress) variants of IBS or may be related to clinical severity still remains unknown.

Mast cells have been frequently considered in the context of allergic and parasite inflammation, but growing and convincing evidence indicates that they also participate in a wide variety of physiological and pathological processes ${ }^{32}$ including the regulation of epithelial barrier, mucosal immune function, motility and gut visceral sensitivity. ${ }^{13} 33$ Such abnormalities in gut function have been reported in IBS and could be partly responsible for the clinical findings in these patients, especially those with predominant diarrhoea, since patients with increased intestinal mast cells, ${ }^{34}$ and up to $70 \%$ of those with systemic mastocytosis, ${ }^{35}$ develop diarrhoea and abdominal discomfort.

The quantitative analysis of mucosal mast cells was based on CD117 positive immunohistochemistry which has shown high correlation with tryptase staining, is not altered by massive degranulation and can be regarded as specific for mast cells in the gut mucosa. ${ }^{36}$ Our results indicate that jejunal mastocytosis $(>20 \mathrm{MC} / \mathrm{hpf})$ is a constant feature in the mucosa of this

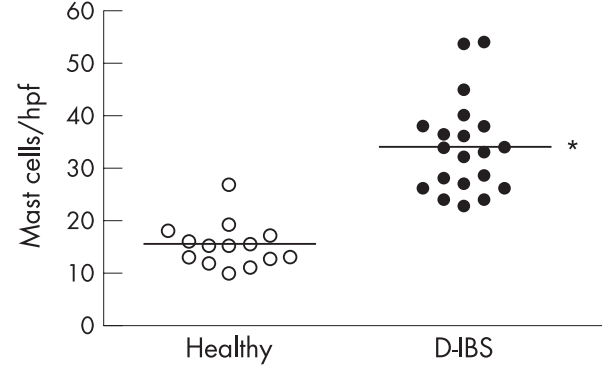

Figure 6 Jejunal mast cells counts. Mast cells were counted in eight contiguous, non-overlapping, histological fields, at $400 \times$, and expressed as mast cells per high power field (hpf) after immunohistochemistry for $c$-kit. D-IBS patients $(n=20)$ showed a significant increase in mast cell numbers compared to healthy volunteers $(n=14)$. Black lines represent median values. ${ }^{*} p<0.001$, Mann Whitney $U$ test.

selected group of patients with D-IBS. Our D-IBS patient group was quite homogeneous and the average profile would be a naive individual experiencing active and mostly severe bowel disturbances, not previously diagnosed or treated, and suffering from moderate psychological stress but no coincident allergic disorders. Increased mast cell numbers and mast cell biological products have been previously described in the terminal ileum and proximal and distal colon of IBS patients. ${ }^{17-19} 29{ }^{30}$ Moreover, increased numbers of mucosal mast cells have been recently described in the duodenal mucosa of patients with diarrhoea, with some of these individuals probably belonging to the D-IBS subgroup. ${ }^{37}$ We cannot exclude the fact that small bowel mast cell hyperplasia may represent an epiphenomenon linked to low-grade mucosal inflammation since there have been conflicting reports describing increased or decreased mast cell numbers in the upper small intestine in disorders such as chronic urticaria, ${ }^{38}$ psoriasis ${ }^{39}$ and coeliac disease. ${ }^{40}$ Biopsies of the upper small bowel are often obtained as part of the clinical evaluation of diarrhoea and, based on routine histopathology, reported as normal. D-IBS may be easily overlooked by the physician following a conventional approach and we suggest that on account of the relative ease of jejunal capsule biopsy sampling and the very high sensitivity and positive predictive values of CD-117 analysis (over 90\% in our study), biopsy sampling as a complementary criterion for the positive diagnosis of D-IBS deserves further evaluation.

Some studies have shown a potential influence of clinical history or age on mucosal mast cell numbers. ${ }^{17}{ }^{24}$ Although our data do not support a correlation between age or gender with mast cell numbers, we acknowledge the relatively low number of participants as a limitation to properly evaluating this aspect. Some questions remain to be answered such as the influence of the clinical course (active or remission), the length of clinical history and the relationship of clinical severity with

Table 3 Gender effect on mast cell counts in the jejunal mucosa

\begin{tabular}{lll}
\hline & Male & Female \\
\hline D-IBS patients & 36.8 (SD 9.3) & 32.7 (SD 9.4) \\
Healthy volunteers & {$[230.3$ (SD 57.9)] } & {$[204.4$ (SD 58.8)] } \\
& {$[5.9$ (SD 5.4) } & 14.5 (SD 3.2) \\
& {$[99.3$ (SD 33.9)] } & {$[90.5$ (SD 19.7)] } \\
\hline
\end{tabular}

No differences in mast cell numbers were observed between male and female participants. D-IBS patients: male, $n=6$; female, $n=14$. Healthy volunteers: male, $n=8$; female, $n=6$. Mast cell numbers are expressed as cells/high power field. Mast cell counts are also expressed, for comparison as cells $/ \mathrm{mm}^{2}$ (in square brackets). Conversion factor: $1 \mathrm{~mm}^{2}=6.249$ high power fields. Values are expressed as mean (SD). 


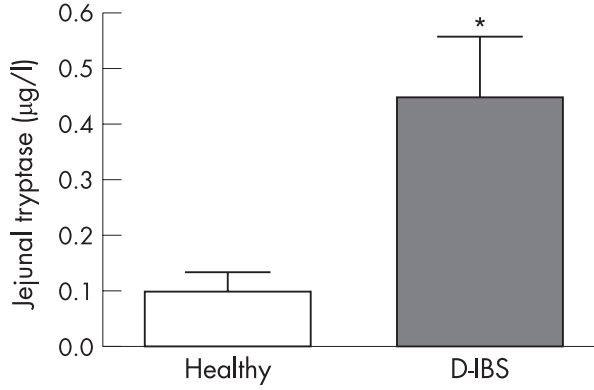

Figure 7 Jejunal luminal tryptase. D-IBS patients $(n=20)$ showed higher tryptase concentration in the jejunal aspirate than healthy volunteers $(n=14)$. Values are expressed as mean (SEM). ${ }^{*} p=0.005$; Mann Whitney $\mathrm{U}$ test.

mucosal mast cell numbers or mast cell phenotype. Again, further studies are warranted to address these and other emerging concerns.

Tryptase is an abundant specific neutral protease of human mast cells that can be measured in various biological fluids and may serve as a useful marker of mast cell activation. ${ }^{42}$ Our study is unique in reporting the association of jejunal mast cell hyperplasia with, only local, in vivo mast cell activation, as disclosed by elevated levels of jejunal luminal tryptase but not serum tryptase. Although mast cells are the only significant source of tryptase in the intestinal mucosa, no correlation between the number of mucosal mast cells and the levels of luminal tryptase was detected. One plausible explanation for these findings is that mast cell activation and secondary release of tryptase may not be a continuous process. In fact, mast cell activation in IBS seems to be more a piecemeal-like phenomenon where slow and selective release of mediators occurs and increased luminal release takes place only in specific settings. Indeed, ultrastructural signs of piecemeal degranulation and in vitro release of mast cell products such as tryptase and histamine have been shown in colonic and ileal biopsies of IBS patients ${ }^{17-19}$ and in some cases of duodenal samples, in patients with chronic diarrhoea. ${ }^{43}$ Although tryptase, via activation of protease-activated receptor-2 or other unrelated mechanisms, is a good candidate to explain some of the prosecretory and pro-inflammatory effects of mast cells, ${ }^{44}{ }^{45}$ other mast cell mediators may be also involved.

The mechanisms, mediators and pathways that may account for mast cell activation and hyperplasia in the jejunum of D-IBS patients remain to be fully characterised. The list of potential candidates is large and growing although the known ability of molecules such as stem cell factor, ${ }^{46} \mathrm{IL}-4,{ }^{46}$ transforming growth factor- $\beta_{1}{ }^{47}$ corticotropin-releasing hormone ${ }^{48}$ and $\operatorname{IgE}^{46}$ to modulate crucial aspects of human mast cell physiology such as secretory activity, growth and maturation, phenotype or migration could make them initial, but not exclusive, favourites.

We have found that D-IBS patients were experiencing higher levels of psychological stress than the control group. Although we did not find a positive correlation between stress levels and mast cell numbers or tryptase release, a suggestive trend was apparent. However, it is well recognised that IBS is a stresssensitive disorder, where life events are strong predictors of clinical exacerbation ${ }^{49}$ and the existence of distorted autonomic patterns along with neuroendocrine abnormalities in the hypothalamic-hypophyseal-adrenal axis $^{50}$ seem to be related to changes that result in the predominant bowel habit (diarrhoea/constipation) and intestinal visceral hyperalgesia. ${ }^{51}$ These observations, consistent with the participation of neurohumoral mediators of stress in the initiation and development of such pathophysiological abnormalities, ${ }^{11}{ }^{52}$ are being substantiated by experimental and clinical studies showing that both stress and corticotropin-releasing hormone regulate intestinal epithelial and immune function via mast cell activation. $^{12} 152253$

Finally, epidemiologic studies suggest that IBS and functional dyspepsia overlap to a greater extent than would be expected by chance alone. ${ }^{20} 21$ In agreement with these proposals, we have found that $70 \%$ of our D-IBS patients fulfilled Rome II criteria for functional dyspepsia. Although extension of mucosal mast cell involvement from the distal colon to the upper gut might be a helpful explanation for the frequent overlap, we did not observe any difference in jejunal mast cell numbers between dyspeptic and non-dyspeptic IBS patients. Although not thoroughly evaluated, others have shown that mast cells were increased in the antrum and corpus of patients with Helicobacter pylori-negative functional dyspepsia $^{54}$ compared to controls. Thus, another key unanswered question is whether patients with dyspepsia and IBS share a similar pathogenesis but different clinical expression.

In conclusion, jejunal mast cell hyperplasia and tryptase release may be frequent and useful findings in non-treated DIBS patients. Their validity as biological markers for D-IBS and usefulness for developing mast cell-related treatment strategies in these patients should be established by further studies.

\section{ACKNOWLEDGEMENTS}

We are grateful to Victoria Cardona and María Rueda for their collaboration in the performance of skin prick tests and to Anna Aparici, Maria Teresa Casaus and Purificación Rodríguez for assistance in Watson capsule management.

\section{Authors' affiliations}

M Guilarte, Allergy Unit and Digestive Diseases Research Unit, Hospital Universitari Vall d'Hebron, Department of Medicine, Universitat Autònoma de Barcelona, Barcelona, Spain

J Santos, C Alonso, M Vicario, L Ramos, C Martínez, F Casellas,

E Saperas, J R Malagelada, Digestive Diseases Research Unit, Department of Gastroenterology, Hospital Universitari Vall d'Hebron, Department of Medicine, Universitat Autònoma de Barcelona, Barcelona, Spain

I de Torres, Department of Pathology, Hospital Universitari Vall d'Hebron, Department of Medicine, Universitat Autònoma de Barcelona, Barcelona, Spain

Grant support: Supported in part by the Spanish Ministry of Sanidad y Consumo, Subdirección General de Investigación Sanitaria, Instituto Carlos III, Fondo de Investigación Sanitaria. JS (F.I.S. 01/3134 and F.I.S. 02/ 0190), CA (CM04/00019) and LR (CM05/00055) were the recipients of these grants.

Competing interests: None.

\section{REFERENCES}

1 Horwitz BJ, Fisher RS. The irritable bowel syndrome. N Engl J Med 2001;344:1846-50.

2 Bercik P, Verdu EF, Collins SM. Is irritable bowel syndrome a low-grade inflammatory bowel disease? Gastroenterol Clin N Am 2005;34:235-45

3 Talley NJ, Spiller R. Irritable bowel syndrome: a little understood organic bowel disease? Lancet 2002;360:555-64.

4 Palsson OS, Drossman DA. Psychiatric and psychological dysfunction in irritable bowel syndrome and the role of psychological treatments. Gastroenterol Clin N Am 2005;34:281-303.

5 Mönnikes $\mathbf{H}$, Tebbe JJ, Hildebrandt $M$, et al. Role of stress in functional gastrointestinal disorders. Evidence for stress-induced alterations in gastrointestinal motility and sensitivity. Dig Dis 2001;19:201-11.

6 Tache Y, Perdue MH. Role of peripheral CRF signalling pathways in stress-related alterations of gut motility and mucosal function. Neurogastroenterol Motil 2004; 16(Suppl 1):137-42.

7 Rao SSC, Hatfield RA, Suls JM, et al. Psychological and physical stress induce differential effects on human colonic motility. Am J Gastroenterol 1998;93:985-90

8 Ford MJ, Camilleri M, Zinsmeister AR, et al. Psychosensory modulation of colonic sensation in the human transverse and sigmoid colon. Gastroenterology 1995; 109:1772-80. 
9 Murray CD, Flynn J, Ratcliffe L, et al. Effect of acute physical and psychological stress on gut autonomic innervation in irritable bowel syndrome. Gastroenterology 2004;127:1695-703.

10 Qiu BS, Vallance BA, Blennerhassett PA, et al. The role of CD4+ lymphocytes in the susceptibility of mice to stress-induced reactivation of experimental colitis. Nat Med 1999:5:1178-82

11 Alonso C, Santos J, Guilarte M, et al. Corticotropin-releasing hormone promotes jejunal proinflammatory responses in IBS patients. Gastroenterology 2004;126(Suppl 2):A703.

12 Santos J, Saperas E, Nogueiras C, et al. Release of mast cell mediators into the jejunum by cold pain stress in humans. Gastroenterology 1998;114:640-8.

13 Santos J, Guilarte M, Alonso C, et al. Pathogenesis of irritable bowel syndrome: the mast-cell connection. Scand J Gastroenterol 2005;40:1-12.

14 Eutamene $\mathbf{H}$, Theodorou V, Fioramonti J, et al. Acute stress modulates the histamine content of mast cells in the gastrointestinal tract through interleukin-1 and corticotropin-releasing factor release in rats. J Physiol 2003;553:959-66.

15 Santos J, Yang PC, Soderholm JD, et al. Role of mast cells in chronic stress induced colonic epithelial barrier dysfunction in the rat. Gut 2001;48:630-6.

16 Stead RH, Dixon MF, Bramwell NH, et al. Mast cells are closely apposed to nerves in the human gastrointestinal mucosa. Gastroenterology 1989;97:575-85.

17 Barbara G, Stanghellini V, De Giorgio R, et al. Activated mast cells in proximity to colonic nerves correlate with abdominal pain in irritable bowel syndrome. Gastroenterology 2004; 126:693-702.

18 Weston AP, Biddle WL, Bhatia PS, et al. Terminal ileal mucosal mast cells in irritable bowel syndrome. Dig Dis Sci 1993;38:1590-5.

19 O'Sullivan M, Clayton N, Breslin NP, et al. Increased mast cells in the irritable bowel syndrome. Neurogastroenterol Motil 2000;12:449-57.

20 Agreus L, Svardsudd K, Nyren O, et al. Irritable bowel syndrome and dyspepsia in the general population: overlap and lack of stability over time. Gastroenterology 1995;109:671-80.

21 Talley NJ, Dennis EH, Schettler-Duncan VA, et al. Overlapping upper and lower gastrointestinal symptoms in irritable bowel syndrome patients with constipation or diarrhea. Am J Gastroenterol 2003:98:2454-9.

22 Guilarte M, Santos J, Alonso C, et al. Corticotropin-releasing hormone (CRH) triggers jejunal mast cell and eosinophil activation in IBS patients. Gastroenterology 2004;126(Suppl 2):A38.

23 Thompson WG, Longstreth GF, Drossman DA, et al. Functional bowel disorders and functional abdominal pain. Gut 1999;45:I143-7.

24 Talley NJ, Stanghellini V, Heading RC, et al. Functional gastroduodenal disorders. Gut 1999;45:|137-42.

25 Holmes TH, Rahe RH. The Social Readjustment Rating Scale. J Psychosom Med 1967:11:213-18.

26 Beck AT, Ward CH, Mendelson M, et al. An inventory for measuring depression. Arch Gen Psychiatry 1961;4:561-71.

27 Francis CY, Morris J, Whorwell PJ. The irritable bowel severity scoring system: a simple method of monitoring irritable bowel syndrome and its progress. Aliment Pharmacol Ther 1997;11:395-402.

28 Bland JM, Altman DG. Measuring agreement in method comparison studies. Stat Methods Med Res 1999;8:135-60.

29 Chadwick VS, Chen W, Shu D, et al. Activation of the mucosal immune system in irritable bowel syndrome. Gastroenterology 2002;122:1778-83.

30 Spiller RC. Postinfectious irritable bowel syndrome. Gastroenterology 2003; 124:1662-71

31 Veress B, Franzen L, Bodin L, et al. Duodenal intraepithelial lymphocyte-count revisited. Scand J Gastroenterol 2004;39:138-44.

32 Gurish MF, Austen F. The diverse role of mast cells. J Exp Med 2001;194:F1-5.

33 Barbara G, Stanghellini V, De Giorgio R, et al. Functional gastrointestinal disorders and mast cells: implications for therapy. Neurogastroenterol Motil $2006 ; 18: 6-17$
34 Cherner JA, Jensen RT, Dubois A, et al. Patients with increased gastrointestinal mast cells also display similar symptoms to IBS patients. Gastrointestinal dysfunction in systemic mastocytosis. A prospective study. Gastroenterology 1988;95:657-67.

35 Jensen RT. Gastrointestinal abnormalities and involvement in systemic mastocytosis. Hematol Oncol Clin North Am 2000;14:579-623.

36 Siegert SI, Diebold J, Ludolph-Hauser D, et al. Are gastrointestinal mucosal mast cells increased in patients with systemic mastocytosis? Am J Clin Pathol 2004; 122:560-5.

37 Jakate S, Demeo M, John R, et al. Mastocytic enterocolitis. Increased mucosal mast cells in chronic intractable diarrhea. Arch Pathol Lab Med 2006;130:362-7

38 Minnei F, Wetzels C, De Hertogh G, et al. Chronic urticaria is associated with mast cell infiltration in the gastroduodenal mucosa. Virchows Arch 2006:448:262-8.

39 Michaëlsson G, Kraaz W, Hagforsen E, et al. Psoriasis patients have highly increased numbers of tryptase-positive mast cells in the duodenal stroma. Br J Dermatol 1997; 136:866-70.

40 Strobel S, Busuttil A, Ferguson A. Human intestinal mucosal mast cells: expanded population in untreated coeliac disease. Gut 1986;24:222-7.

41 Dunlop SP, Jenkins D, Spiller RC. Age-related decline in rectal mucosal lymphocytes and mast cells. Eur J Gastroenterol Hepatol 2004;16:1001-5.

42 Schwartz LB, Metcalfe DD, Miller JS, et al. Tryptase levels as an indicator of mastcell activation in systemic anaphylaxis and mastocytosis. N Engl J Med 1987;316:1622-6.

43 Crivellato E, Ribatti D, Mallardi F, et al. Granule changes of human and murine endocrine cells in the gastrointestinal epithelia are characteristic of piecemeal degranulation. Anat Rec 2002;268:353-9.

44 Jacob C, Yang PC, Darmoul D, et al. Mast cell tryptase controls paracellular permeability of the intestine. J Biol Chem 2005;36:31936-48.

45 Steinhoff M, Vergnolle N, Young SH, et al. Agonists of proteinase-activated receptor 2 induce inflammation by a neurogenic mechanism. Nat Med 2000;6:151-8

46 Galli SJ, Kalesnikoff J, Grimbaldeston MA, et al. Mast cells as "tunable" effector and immunoregulatory cells: recent advances. Annu Rev Immunol 2005;23:749-86.

47 Gebhardt T, Lorentz A, Detmer F, et al. Growth, phenotype, and function of human intestinal mast cells are tightly regulated by transforming growth factor B1. Gut 2005; 54:928-34.

48 Cao J, Cetrulo CL, Theoharides TC. Corticotropin-releasing hormone induces vascular endothelial growth factor release from human mast cells via the cAMP/ protein kinase A/p38 mitogen-activated protein kinase pathway. Mol Pharmacol 2006:69:998-1006

49 Bennett EJ, Tennant CC, Piesse C, et al. Level of chronic life stress predicts clinical outcome in irritable bowel syndrome. Gut 1998;43:256-61

50 Dinan TG, Quigley EMM, Ahmed SMM, et al. Hypothalamic-pituitary-gut axis dysregulation in irritable bowel syndrome: plasma cytokines as a potential biomarker? Gastroenterology 2006;130:304-11.

51 Mayer EA, Naliboff BD, Chang L, et al. Stress and the gastrointestinal tract. V. Stress and irritable bowel syndrome. Am J Physiol Gastrointest Liver Physiol 2001;280:G519-24

52 Fukudo S, Nomura T, Hongo M. Impact of corticotropin-releasing hormone on gastrointestinal motility and adenocorticotropic hormone in normal controls and patients with irritable bowel syndrome. Gut 1998;42:845-9.

53 Santos J, Saunders PR, Hanssen NP, et al. Corticotropin-releasing hormone mimics stress-induced colonic epithelial pathophysiology in the rat. Am J Physiol 1999:277:G391-9.

54 Hall W, Buckley M, Crotty P, et al. Gastric mucosal mast cells are increased in Helicobacter pylori-negative functional dyspepsia. Clin Gastroenterol Hepatol 2003;1:363-9. 